\title{
Identification of baboon microRNAs expressed in liver and lymphocytes
}

\author{
Genesio M Karere1, Jeremy P Glenn'1, John L VandeBerg1,2 and Laura A Cox *1,2
}

\begin{abstract}
Background: MicroRNAs (miRNAs) are small noncoding RNAs ( 22 nucleotides) that regulate gene expression by cleaving mRNAs or inhibiting translation. The baboon is a well-characterized cardiovascular disease model; however, no baboon miRNAs have been identified. Evidence indicates that the baboon and human genomes are highly conserved; based on this conservation, we hypothesized that comparative genomic methods could be used to identify baboon miRNAs.
\end{abstract}

Methods: We employed an in silico comparative genomics approach and human miRNA arrays to identify baboon expressed miRNAs in liver $(n=6)$ and lymphocytes $(n=6)$. Expression profiles for selected miRNAs in multiple tissues were validated by RT-PCR.

Results: We identified in silico 555 putative baboon pre-miRNAs, of which $41 \%$ exhibited $100 \%$ identity and an additional $58 \%$ shared more than $90 \%$ sequence identity with human pre-miRNAs. Some of these miRNAs are primatespecific and are clustered in the baboon genome like human miRNA clusters. We detected expression of 494 miRNAs on the microarray and validated expression of selected miRNAs in baboon liver and lymphocytes by RT-PCR. We also observed miRNA expression in additional tissues relevant to dyslipidemia and atherosclerosis. Approximately half of the miRNAs expressed on the array were not predicted in silico suggesting that we have identified novel baboon miRNAs, which could not be predicted using the current draft of the baboon genome.

Conclusion: We identified a subset of baboon miRNAs using a comparative genomic approach, identified additional baboon miRNAs using a human array and showed tissue-specific expression of baboon miRNAs. Our discovery of baboon miRNAs in liver and lymphocytes will provide resources for studies on the roles of miRNAs in dyslipidemia and atherosclerosis, and for translational studies.

\section{Background}

MicroRNAs (miRNAs) are endogenous, small $(\sim 22$ nucleotides), non-coding RNAs that are transcribed by RNA polymerase II from intergenic, intronic or exonic regions of the genome [1]. Primary miRNA (pri-miRNA) transcripts are processed into precursor miRNAs (premiRNAs) in the cell nucleus by Drosa and Pasha protein complexes [2-4]. The pre-miRNAs are exported by exportin-5 to the cytoplasm $[5,6]$ where an RNase III endonuclease, Dicer, cleaves the hair-structure in the pre-miRNA into mature doubled-stranded miRNAs [5]. The single stranded $5^{\prime}$ terminus of the mature miRNA, is recruited into the RNA-induced silencing complex (RISC) ([7].

\footnotetext{
* Correspondence: Icox@sfbrgenetics.org

1 Department of Genetics, Southwest Foundation for Biomedical Research, San Antonio, 7620 NW Loop 410, TX 78227, USA

Full list of author information is available at the end of the article
}

Guided by RISC, the miRNAs silence gene expression by degrading target mRNA when there is complete basepairing, or by inhibiting translation when there is imperfect binding to the 3 ' untranslated region (UTR) $[8,9]$. Some miRNAs also bind to 5 ' UTRs [10]. miRNAs exhibit temporal and spatial expression patterns and are implicated in diverse cell functions for development, proliferation and differentiation [2,11,12]. Moreover, miRNAs show aberrant expression in diseases such as cancer, diabetes and cardiac diseases [13-17]. Recent studies indicate that the up-regulation of miR-335 and 122 is associated with lipid metabolism in obese mice $[18,19]$. This suggests that miRNA dysregulation may play a role in disease phenotypes and that miRNAs may be important biomarkers for disease diagnosis [20,21].

miRNAs are highly conserved across species, particularly in the first 8 nucleotides (nts) at the 5 ' end known as 
the 'seed region' [22,23]. Using the conserved regions of miRNAs, computational analyses have augmented the prediction of miRNAs in many different species. As of September 2009, 10,883 miRNAs have been deposited in the microRNA database miRBase (Release 14: http:// www.mirbase.org) [24], including 750 human, 604 Chimpanzee and 483 rhesus macaque miRNAs. In addition multiple miRNAs are conserved as clusters in genomes, some of these clusters have common functional roles, such as the testicular oncogenic miR371/373 human cluster [25]. The evolutionary conservation of miRNAs among species suggests that miRNAs have conserved biological functions.

The baboon is a well-characterized model for human biomedical studies including cardiovascular disease, however no baboon miRNAs have been identified and reported in the miRBase. In the present study we compared human precursor miRNA (pre-miRNA) sequences with draft baboon genome sequence data to identify putative baboon miRNAs. After identifying the baboon miRNAs in-silico, we determined expression profiles of baboon liver and lymphocytes miRNAs using a human miRNA microarray. miRNA expression profiles for select miRNAs in baboon tissues were validated using RT-PCR. Our results indicate that cross-species sequence alignment can be used to identify putative miRNAs in an unannotated genome. In addition, these results show the miRNAs that are expressed in baboon liver and lymphocytes and the differences in these miRNA expression profiles. The findings from these studies are relevant to future studies of the roles of miRNAs in dyslipidemia and atherosclerosis; liver is a primary target organ for cardiovascular disease, whereas lymphocytes are an easily accessible diagnostic sample in humans.

\section{Methods \\ In silico identification of putative baboon miRNAs}

Human pre-miRNA sequences were accessed from the University of California, Santa Cruz (UCSC) Genome Browser [26,27] utilizing the Table function for SNO/ miRNAs [28]. The human pre-miRNA data in the Genome Browser are from the miRBase Sequence Database at the Wellcome Trust Sanger Institute [29,30]. Human pre-miRNA sequences were used to query the NCBI trace archives of the Papio hamadryas whole genome sequence using the BLASTN program http:// blast.ncbi.nlm.nih.gov/Blast.cgi. BLAST alignment was optimized for highly similar sequences. Algorithm parameters included automatically adjusting for short input sequences, an expected threshold of 10, word size of 28 , match/mismatch scores of $1-2$, linear gap costs, and regional low complexity filtering. In addition, baboon to human sequence alignments were filtered based on baboon sequence quality scores greater than 50. Pre- dicted baboon pre-miRNAs are shown in Additional File 1 .

\section{Identification of baboon pre-miRNA genomic clusters}

Human genomic DNA regions containing pre-miRNA clusters were identified by UCSC genome browser. Genomic DNA for each cluster was aligned with the draft assembly of the baboon genome sequence in the trace archive http://blast.ncbi.nlm.nih.gov/Blast.cgi using the BLAST alignment tool [31]. To validate baboon draft assembly alignment, the baboon genomic DNA region was aligned against the human genome using the BLAT alignment tool [27]. In addition, human genomic DNA was aligned with the rhesus genome using the BLAT alignment tool.

Baboon genomic regions were aligned to regions of the other species by searching for homologous human miRNAs in the Baboon Test Genome Browser Gateway hosted by the UCSC http://genome-test.cse.ucsc.edu. BLAST was then used to search for baboon DNA sequences in the human genome for homologous region. Regional tracks of chimpanzee, rhesus, mouse and rat are also presented.

\section{Tissue Collection}

All procedures were approved by the Southwest Foundation for Biomedical Research (SFBR) Institutional Animal Care and Use Committee and conducted in Association for Assessment and Accreditation of Laboratory Animal Care approved facilities. Liver biopsies and blood were collected from six baboons. Baboons were sedated with ketamine $(10 \mathrm{mg} / \mathrm{kg})$, given atropine $(0.025 \mathrm{mg} / \mathrm{kg})$ and intubated. Anesthesia was induced and maintained with isoflurane (1-2\%). Blood pressure was measured by automated arm cuff (Collin) and oxygen saturation, heart rate, and respiration was monitored by pulse oximetry. A Southwest National Primate Research Center staff veterinarian collected biopsies. During post biopsy recovery analgesia was provided in the form of Stadol, $0.15 \mathrm{mg} / \mathrm{kg}$, bid, for 3 days and ampicillin, $25 \mathrm{mg} /$ day for 10 days. Liver, testis, femoral and coronary arteries, omental fat, and cerebrum were also collected opportunistically from one baboon after euthanization at necropsy. Tissue samples were quick frozen in liquid $\mathrm{N}_{2}$ and stored at $-80^{\circ} \mathrm{C}$. Lymphocytes were isolated from blood and stored at $80^{\circ} \mathrm{C}$.

\section{Sample preparation}

Total RNA was isolated from liver $(\mathrm{n}=6)$ and lymphocytes $(n=6)$ of adult baboons and also isolated from testis, femoral and coronary arteries, omental fat, and cerebrum of an adult baboon using RNeasy kit (Qiagen) according to the manufacturer's protocol. Fresh baboon tissues were snap-frozen in liquid nitrogen and stored at - 
$80^{\circ} \mathrm{C}$ until RNA was extracted. RNA was quantified using the protocol in the RiboGreen kit (Invitrogen). A standard curve was created from known concentrations of serial diluted rRNA and used to interpolate and determine the concentrations of RNA from the baboon samples.

\section{miRNA expression profiling}

Baboon miRNAs were hybridized to a miRNA Beadchip Human Illumina Beadchip array version 2) containing 1,146 probes following the manufacturer's protocol http:/ /www.illumina.com/technology/microrna assay.ilmn.

Briefly, $500 \mathrm{ng}$ of total RNA was polyadenylated using a biotinylated oligo-dT primer, containing a universal PCR primer site at 5 'end. Biotinylated cDNAs were generated by reverse transcription and hybridized to miRNA-specific oligos. Each oligo contains a 5 '-end universal PCR priming site, an address sequence complementary to the capture sequence on the array bead and a 3' end microRNA-specific sequence. After hybridization, the mixture was bound to streptavidin-containing paramagnetic particles and unhybridized mixture washed off. Using a pair of universal primers, the hybridized mixture was amplified and a single-strand complementary to the array sequence fluorescently labeled. The labeled PCR products were hybridized to the array capture sequence attached to the array beads. Using a BeadScan reader (Illumina), array signal intensities were measured in duplicate using the embedded channels. The signal intensity corresponds to the quantity of respective miRNA in a sample.

\section{Data analysis}

Data analysis was performed using a BeadStudio software (Illumina version 3.1.3.0). The miRNA intensity data were filtered by applying a detection threshold of $\mathrm{p}<0.05$, which corresponds to the mean signal intensity from each probe that is significantly different from the mean of a baseline control probe. The analyzed data was up-loaded into a spreadsheet and further analysis performed. The mean detection values from a set of 12 redundant oligos probing single miRNA were averaged and signal intensities with detection $\mathrm{p}$-values $<0.05$ were considered expressed.

\section{Design of primers for miRNA RT-PCR}

Primer pairs and miRNA sequences used for RT-PCR are presented in Additional file 1. For the primer design, we followed previous description [32]. Primers for the RTPCR included a stem-loop RT primer containing 4-6 nts at the 3 ' end complementary to the miRNA molecule, a miRNA-specific forward primer, and a universal reverse primer. Synthetic miRNA oligonucleotides were purchased from Integrated DNA Technologies (IDT).

\section{Reverse Transcription reactions}

For the RT-PCR, 80 ng of RNA was reverse transcribed to generate miRNA specific first-strand cDNA. A 20 ul RT reaction also included $1 \times$ PCR buffer, $0.5 \mathrm{mM}$ dNTP, 0.5 $\mathrm{U}$ RNase inhibitor, $1.5 \mathrm{mM} \mathrm{MgCl}_{2}, 1 \mathrm{uM}$ reverse transcription primer, $0.5 \mathrm{uM}$ DTT and $0.25 \mathrm{U}$ of Superscript III reverse transcriptase. The RT-PCR mixture was incubated in an $\mathrm{AB} 9700$ Thermocycler for $30 \mathrm{~min}$ at $16^{\circ} \mathrm{C}, 30$ min at $42^{\circ} \mathrm{C}, 5 \mathrm{~min}$ at $85^{\circ} \mathrm{C}$ and held at $4^{\circ} \mathrm{C}$. Controls included a master mix with no reverse transcriptase.

\section{PCR}

Two micro liters of miRNA specific cDNA was amplified in $\mathrm{AB} 9700$ Thermocycler in a 96-well plate using the following profile: denaturation for $5 \mathrm{~min}$ at $95^{\circ} \mathrm{C}$, followed by 35 cycles of $30 \mathrm{sec}$ at $94^{\circ} \mathrm{C}, 45 \mathrm{sec}$ at $60^{\circ} \mathrm{C}, 30 \mathrm{sec}$ at $72^{\circ} \mathrm{C}$ and final extension for $7 \mathrm{~min}$ at $72^{\circ} \mathrm{C}$. Each PCR reaction $(20 \mathrm{ul})$ contained $1 \times$ PCR buffer, $0.8 \mathrm{mM} \mathrm{dNTP}$, $1 \mathrm{uM}$ of paired primers, $3.5 \mathrm{mM} \mathrm{MgCl}_{2}$ and $0.25 \mathrm{U}$ ExTaq polymerase (Takara Bio Inc.). PCR products in a denaturing loading dye were incubated at $95^{\circ} \mathrm{C}$ for $5 \mathrm{~min}$, chilled on ice and size-fractionated on a $3 \%$ agarose gel in $1 \times$ TBE buffer at $6 \mathrm{~V} / \mathrm{cm}$. The gel was stained with ethidium bromide before visualization under UV light. For the PCR, the negative control consisted of a master mix with no cDNA.

\section{Results}

\section{Prediction of Baboon genome miRNAs}

Alignment of published human precursor miRNA sequences from the miRBase database http://www.mirbase.org with the baboon genome sequences predicted 555 baboon miRNAs. Information on the predicted baboon miRNAs including names, genomic coordinates, length, mismatches and percent identity with human premiRNA sequences are available in Additional file 2. The length of the predicted pre-miRNAs ranged from 28 to 150 nts with an average of 81 nts. Only 54 (9.7\%) of the total predicted miRNAs had more than $4 \mathrm{bp}$ mismatches between human and baboon sequences (Figure 1). Of the 555 predicted baboon miRNAs, 227 (40.9\%) shared 100\% sequence identity with the human pre-miRNAs and 319 (57.5\%) had greater than $90 \%$ and less than $100 \%$ identity with human pre-miRNAs (Table 1).

\section{miRNA expression profiling}

Expression profiling of baboon liver $(n=6)$ and lymphocyte $(n=6)$ miRNAs using a miRNA microarray detected expression of 494 miRNAs (Table 2 and Additional file 3). Sixty-eight (13.8\%) were expressed only in lymphocytes and $8(1.6 \%)$ were expressed only in liver. Of the 494 expressed miRNAs, 205 (41.5\%) were predicted by in-silico analysis (Table 3), while 289 are likely new baboon miRNA identified through the human miRNA array. 
Table 1: Conservation of pre-miRNAs sequences between human and baboon.

\begin{tabular}{lccccccccc}
\hline Alignment identity (\%) & $\mathbf{1 0 0}$ & $\mathbf{9 9 - 9 8}$ & $\mathbf{9 7 - 9 6}$ & $\mathbf{9 5 - 9 4}$ & $\mathbf{9 3 - 9 2}$ & $\mathbf{9 1 - 9 0}$ & $\mathbf{8 9 - 8 8}$ & $\mathbf{8 7}$ & Total \\
\hline Number miRNAs & 227 & 124 & 88 & 61 & 33 & 13 & 8 & 1 & 555 \\
& & & & & & & & & \\
& 40.9 & 22.3 & 15.9 & 11 & 5.9 & 2.3 & 1.4 & 0.2 & 100 \\
\hline Percent miRNAs & & &
\end{tabular}

\section{Validation of expressed miRNAs}

Validation of liver and lymphocyte miRNA microarray expression profiles by Reverse Transcription-PCR (RTPCR) in liver and lymphocytes was performed for a subset of expressed and undetected miRNAs. We confirmed expression of miR21, 26b, 30a-5p, 760, and 16-1 (Figure 2) and lack of detectable expression for miR302a, 648, and 373. Expression profiles for additional tissues (testis, femoral and coronary arteries, omental fat and cerebrum) showed expression of miR21, 26b, 30a-5p and 760, and tissue specific expression of miR16-1. miRNAs that did not show a detectable signal on the miRNA array did not show a product using RT-PCR validating the specificity of the miRNA array data for both the expressed and undetected miRNAs.

\section{miRNA gene clusters}

Previous studies have demonstrated that miRNA genes may exhibit clustering in the genome [33] and that some clusters are primate specific [34]. Our analyses confirm that the miRNA clusters on chromosome (chr) 19 and X are conserved in primates including rhesus macaque and baboon but not in non-primate mammals such as rat and mouse (Figure 3). Both clusters are localized at a subtelomeric region on the $\mathrm{q}$-arm that displays evolutionary conservation among 17 vertebrate species. The miRNA cluster on chr 19 is located at 58,831,904-58,961,623 bp, a

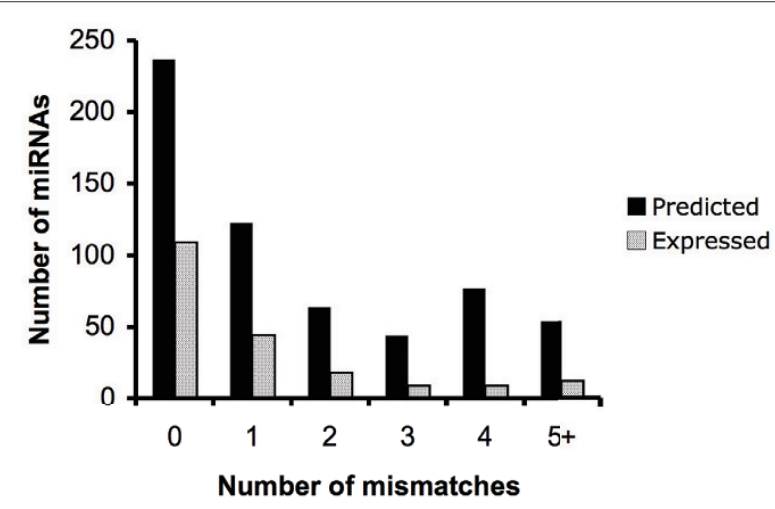

Figure 1 The number of mismatches compared to the number of predicted and expressed baboon miRNAs. The $x$-axis indicates the number of nucleotide differences when comparing baboon and human pre-miRNA sequences; the $y$-axis denotes the number of predicted (black) and expressed (gray) pre-miRNAs. region harboring human and rat QTLs including a QTL encoding serum cholesterol trait. The chromosome $\mathrm{X}$ cluster is localized to $146,059,514-146,180,617 \mathrm{bp}$ and includes QTLs encoding insulin and stress responses. Although clustered miRNA family members tend to have similar expression patterns, in this study miR302a* was expressed in baboon liver and lymphocytes while 302a was not detected. We also observed that some chr. 9 cluster members (miR521, 520e, 373*, 373, 367) were not detected in both baboon liver and lymphocytes; however, miR514 cluster member on chr $\mathrm{X}$ was expressed in the liver and not detected in lymphocytes.

\section{Discussion}

Previous studies have identified and quantified miRNAs in various species and in some cases shown that miRNA influences disease susceptibility. For quantification and identification of miRNAs, cloning and sequencing, northern blotting and primer extension methodologies have been employed. Recently, arrays have been used for high throughput quantification of miRNA expression in different normal and diseased tissues, e.g. neuronal differentiation $[35,36]$. The principle objective of this study was to identify and quantify baboon miRNAs expressed in liver that may be relevant to lipid metabolism in baboon and determine if these liver miRNAs could also be detected using an easily accessible RNA source, lymphocytes. Due to the high degree of conservation observed between human and baboon miRNA sequences using in silico analyses, we used a human miRNA microarray to identify miRNAs expressed in baboon liver and lymphocytes. We then validated the expression of a select number of miRNAs using RT-PCR. Moreover, we determined the expression of the selected miRNAs in tissues relevant to dyslipidemia and cardiovascular disease.

Table 2: Summary of miRNA expression profiling for baboon liver and lymphocyte RNA.

\begin{tabular}{lll}
\hline miRNA Expression & Number & Percent \\
\hline Both Liver and Lymphocytes & 418 & 84.6 \\
Liver Only & 8 & 1.6 \\
Lymphocytes Only & 68 & 13.8 \\
Total miRNAs Expressed & 494 & 100.0 \\
\hline
\end{tabular}


Table 3: Summary of miRNAs predicted and expressed in baboon liver and lymphocyte RNA.

\begin{tabular}{lll}
\hline miRNA Expression & Number & Percent \\
\hline Both Liver and Lymphocytes & 189 & 92.0 \\
Liver Only & 2 & 1.0 \\
Lymphocytes Only & 14 & 7.0 \\
Total miRNAs Expressed & 205 & 100.0 \\
\hline
\end{tabular}

In this study we identified and quantified miRNA using a combined approach of computational analysis and miRNA array. Of the predicted baboon miRNAs $(\mathrm{N}=$ 555), $40.9 \%$ sequences were identical to human pre-miRNAs. This is similar to $38.1 \%$ reported for rhesus macaque [37] and is consistent with alignment of DNA sequences between macaque and baboon showing on average $98 \%$ identity [38]. miRNAs $(\mathrm{N}=494)$ were expressed in baboon liver and lymphocytes. The expressed miRNAs include miR-133, 208, and 21, which have validated targets for cardiovascular system [13]. We also detected expression of miRNA-335 and 122, which are associated with lipid metabolism [19]. Of the 494 expressed miRNAs, $58.5 \%$ were not predicted through in-

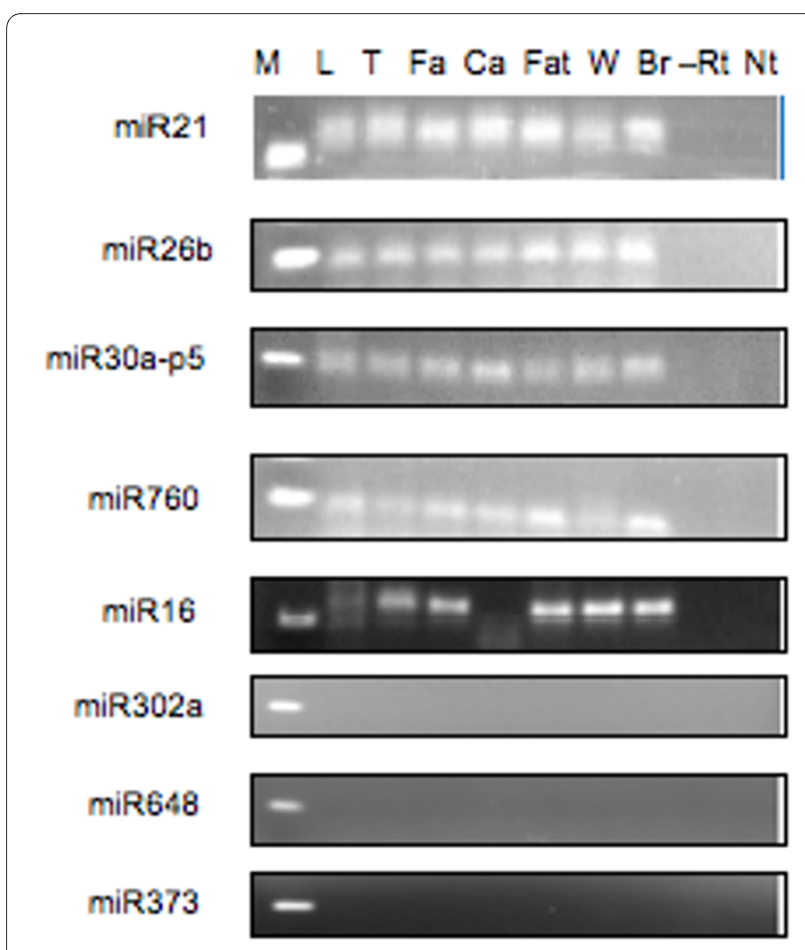

Figure 2 miRNA expression in baboon tissues. miRNA RT-PCR products generated by stem-loop RT-PCR were size-fractionated in a 3\% agarose gel. Samples include: M: 50 bp marker, L: liver, T: testis, Fa: femoral artery, Ca: coronary artery, Fat: omental fat, W: lymphocytes, Br: brain, -Rt: RT control without reverse transcriptase, Nt: non-template control. silico analysis. This fraction may constitute new miRNAs not available in the current baboon draft genome assembly. Moreover, 350 miRNAs were predicted through alignment of human miRNA sequences with draft baboon genome sequences, but were not expressed in the miRNA array. Possibly this is due to tissue specificity of the miRNAs or miRNA expression below the detection limit. Completion of the baboon genome sequence, anticipated at $6 \times$ coverage, will enhance the prediction of putative miRNAs.

Previous studies have demonstrated that while miRNAs are conserved across many species, the expression pattern may be lineage and/or tissue/cell specific $[39,40]$. Of the total 494 expressed baboon miRNAs, $13.8 \%$ were expressed only in the lymphocytes, while $1.6 \%$ were detected only in the liver. We confirmed by RT-PCR that some miRNAs such as miR16-1 show more restrictive expression patterns. Further the RT-PCR results validate the results of the microarray assay; miRNAs that were expressed in the array were successfully amplified by RTPCR and vis-à-vis miRNAs not detected. Moreover, expression of some miRNA is species-specific. While miR648 and 373 were reportedly expressed in the rhesus liver [37], these miRNAs were not detected in baboon liver using miRNA arrays or RT-PCR. Altogether we confirm previous evidence that miRNAs exhibit spatial and species-specific expression patterns.

A new class of unconserved miRNAs, existing in clusters, has been identified in many species. A miRNA cluster is defined as miRNAs exhibiting the same orientation and not separated by a transcriptional unit or a miRNA in the opposite direction [41]. Two large miRNA clusters on human chr $19(\mathrm{~N}=54)$ and $\mathrm{X}(\mathrm{N}=10)$ are conserved between human and chimpanzee and are specifically expressed in placenta and testis [42]. We sought to determine if these clusters are conserved in baboon as in other primates. In addition, we investigated whether the cluster members are expressed in baboon liver and lymphocytes. We observed that miRNA clusters on chr X and 19 are primate-specific and are conserved between human, chimpanzee, rhesus and baboon genomes. The absence of these clusters in non-primate species including rat and mouse indicates recent evolution in the primate lineage. Integration of the baboon draft genome http://genometest.cse.ucsc.edu/ with previously published baboon linkage map [43,44] and comparison with the human and rhesus genomes shows complete synteny among human, rhesus and baboon for chromosomes X and 19. In contrast a smaller adjacent miRNA cluster (miR371, 2,3) on chr $19(58,983000-58,983500 \mathrm{bp})$ is conserved in human, rhesus and rat, but not mouse [37]. In addition Yue and colleagues observed that miRNA clusters on chr 4 and 13 are also conserved in human, rhesus, rat and mouse. We observed conservation of these clusters in the baboon 


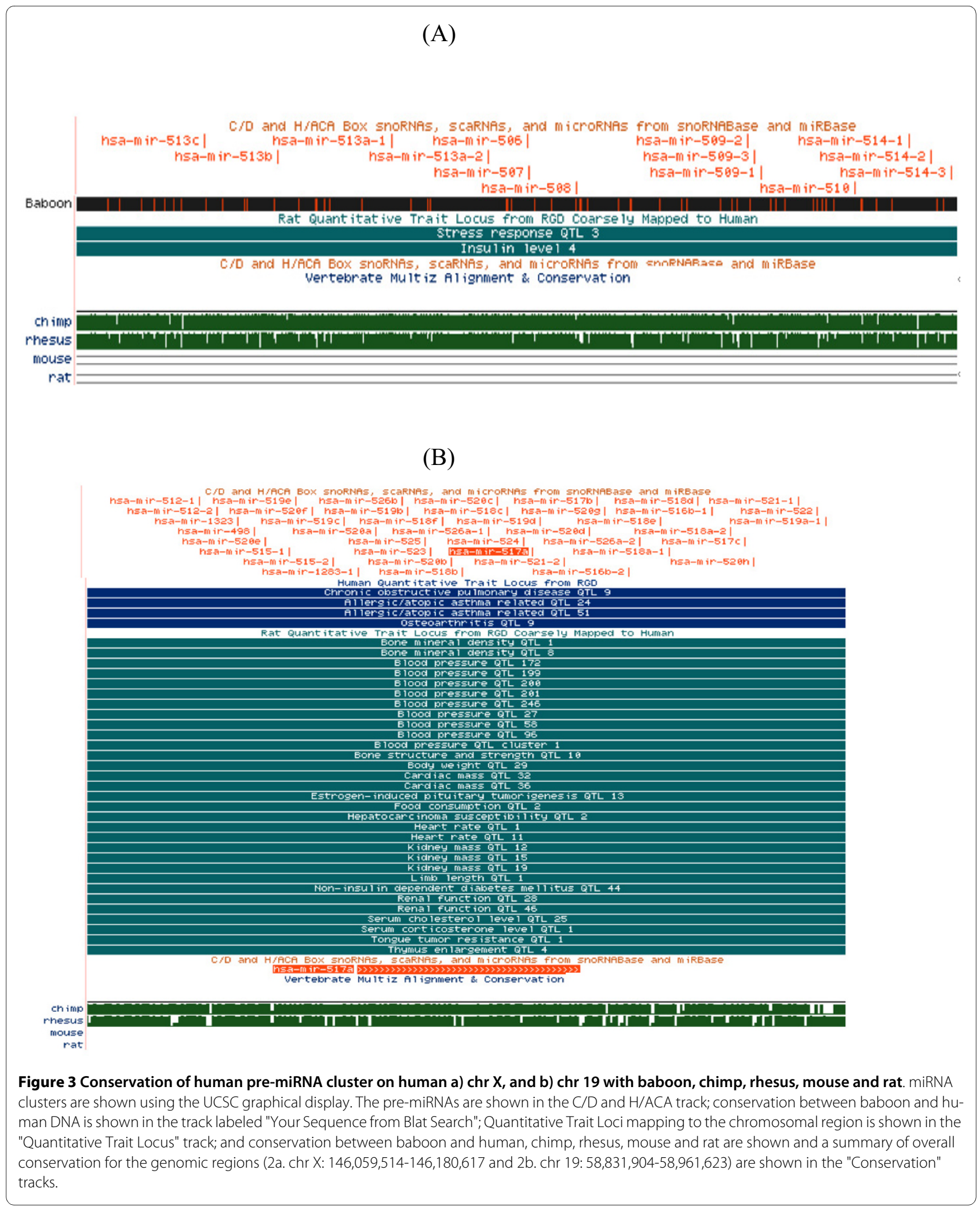

genome (data not shown). Altogether, this information suggests that while a subset of miRNA clusters are primate specific, some miRNA duplications occurred before the divergence of primate and rodent lineages.
Previous studies have reported that miRNA clusters exhibit linked expression patterns, suggesting shared cisregulatory elements, and/or a polycistronic transcription [45]. This observation of linked expression patterns was 
affirmed in this study. For example, miRNA cluster members on chr 19 were down regulated while miR302a and 302d gene family members on human chr 4 and miR17, 18 , and 19 on chr 13 [37] were expressed in baboon liver and lymphocytes. This observation suggests that expression of some miRNAs is closely linked via coordinated regulation of transcription rather than post-transcriptional modification or stability. Further, we noted that miR-514, a cluster member on the $\mathrm{X}$ chromosome was differentially detected in baboon liver and lymphocytes. Interestingly, miR-514 is known to have different copy numbers among primate species; three copies in human, four in chimpanzee and one in other primates [46], an indication that miRNA duplications may exhibit an evolutionary temporal pattern.

\section{Conclusion}

We have used a combined approach of computational prediction and microarray analysis to identify and quantify baboon miRNAs. A search of homologous human pre-miRNA sequences in the draft baboon genome sequence $(2 \times$ coverage) predicted 555 baboon miRNAs. miRNAs $(\mathrm{N}=494)$ were expressed in baboon liver and lymphocytes using a human miRNA Beadchip. Of the 494 miRNAs expressed on the array, $41.5 \%$ were predicted by bioinformatics analysis indicating more than half of the expressed miRNAs were not predicted. This observation may be attributed to the status of the draft baboon genome sequence and that use of a microarray from a closely related species is important to discovering miRNA genes of an unannotated genome.

Our discovery of baboon miRNAs will provide resources for studies on the roles of miRNAs in dyslipidemia and atherosclerosis in tissues not accessible in humans. In addition the discovery of miRNAs in lymphocytes, which are easily accessible in humans, will be fundamental for translational studies.

\section{Additional material}

Additional file 1 Primer sequences. Information on primer sequences used to perform RT-PCR including the miRNA-specific forward and RT primer sets and universal reverse primers.

Additional file 2 Predicted baboon miRNAs. Information on predicted baboon miRNAs including names, genomic coordinates, length, mismatches and percent identity with human pre-miRNA sequences.

Additional file $\mathbf{3}$ miRNAs array data. The file provides information on Illumina symbol, target ID, normalized expression intensity, detection pvalue, chromosome localization, probe and mature miRNA sequences. Detection p-value is calculated by the BeadStudio to determine significant level of expression intensity above baseline. For this study, p-value threshold was set at 0.05. miRNA with a p-value below the threshold was considered expressed.

\section{Competing interests}

The authors declare that they have no competing interests.
Authors' contributions

GMK, JPG and LAC participated in the conception and design of the experiments. LAC carried out the in silico prediction and analysis of miRNAs. GMK and JPG performed the experiments and data analyses. All authors contributed to writing this manuscript and all have read and approved the final manuscript.

\section{Acknowledgements}

This work was supported by National Institutes of Health grants P01 HL02897227, P01 HL028972-27S1 and P51 RR013986. This investigation was conducted in part in facilities constructed with support from Research Facilities Improvement Program Grant Number C06 RR013556 and C06 RR015456 from the National Center for Research Resources, National Institutes of Health.

\section{Author Details}

'Department of Genetics, Southwest Foundation for Biomedical Research, San Antonio, 7620 NW Loop 410, TX 78227, USA and 2Southwest National Primate Research Center, Southwest Foundation for Biomedical Research, San Antonio, 7620 NW Loop 410, TX 78227, USA

Received: 22 April 2010 Accepted: 1 July 2010

Published: 1 July 2010

\section{References}

1. Rodriguez A, Griffiths-Jones S, Ashurst JL, Bradley A: Identification of mammalian microRNA host genes and transcription units. Genome Res 2004, 14(10A):1902-1910.

2. Lee RC, Feinbaum RL, Ambros V: The C. elegans heterochronic gene lin-4 encodes small RNAs with antisense complementarity to lin-14. Cell 1993, 75(5):843-854

3. Lee Y, Kim M, Han J, Yeom KH, Lee S, Baek SH, Kim VN: MicroRNA genes are transcribed by RNA polymerase II. EMBO J 2004, 23(20):4051-4060.

4. Cai $\mathrm{X}$, Hagedorn $\mathrm{CH}$, Cullen BR: Human microRNAs are processed from capped, polyadenylated transcripts that can also function as mRNAs. RNA 2004, 10(12):1957-1966.

5. Bohnsack MT, Czaplinski K, Gorlich D: Exportin 5 is a RanGTP-dependent dsRNA-binding protein that mediates nuclear export of pre-miRNAs. RNA 2004, 10(2):185-191.

6. Yi R, Qin Y, Macara IG, Cullen BR: Exportin-5 mediates the nuclear export of pre-microRNAs and short hairpin RNAs. Genes Dev 2003, 17(24):3011-3016

7. Maniataki E, Mourelatos Z: A human, ATP-independent, RISC assembly machine fueled by pre-miRNA. Genes Dev 2005, 19(24):2979-2990.

8. Ambros $V$ : The functions of animal microRNAs. Nature 2004, 431(7006):350-355

9. Gregory RI, Yan KP, Amuthan G, Chendrimada T, Doratotaj B, Cooch N, Shiekhattar R: The Microprocessor complex mediates the genesis of microRNAs. Nature 2004, 432(7014):235-240.

10. Miranda KC, Huynh T, Tay Y, Ang YS, Tam WL, Thomson AM, Lim B, Rigoutsos I: A pattern-based method for the identification of MicroRNA binding sites and their corresponding heteroduplexes. Cell 2006, 126(6):1203-1217.

11. Ji R, Cheng Y, Yue J, Yang J, Liu X, Chen H, Dean DB, Zhang C: MicroRNA expression signature and antisense-mediated depletion reveal an essential role of MicroRNA in vascular neointimal lesion formation. Circ Res 2007, 100(11):1579-1588.

12. Giraldez AJ, Cinalli RM, Glasner ME, Enright AJ, Thomson JM, Baskerville S, Hammond SM, Bartel DP, Schier AF: MicroRNAs regulate brain morphogenesis in zebrafish. Science 2005, 308(5723):833-838

13. Latronico MV, Catalucci D, Condorelli G: Emerging role of microRNAs in cardiovascular biology. Circ Res 2007, 101(12):1225-1236.

14. Liu X, Cheng Y, Zhang S, Lin Y, Yang J, Zhang C: A necessary role of miR221 and miR-222 in vascular smooth muscle cell proliferation and neointimal hyperplasia. Circ Res 2009, 104(4):476-487.

15. Li W, Xie L, He X, Li J, Tu K, Wei L, Wu J, Guo Y, Ma X, Zhang P, Pan Z, Hu X, Zhao Y, Xie H, Jiang G, Chen T, Wang J, Zheng S, Cheng J, Wan D, Yang S, Li $Y, \mathrm{Gu}$ J: Diagnostic and prognostic implications of microRNAs in human hepatocellular carcinoma. Int J Cancer 2008, 123(7):1616-1622.

16. Care A, Catalucci D, Felicetti F, Bonci D, Addario A, Gallo P, Bang ML, Segnalini P, Gu Y, Dalton ND, Elia L, Latronico MV, Hoydal M, Autore C, Russo MA, Dorn GW, Ellingsen O, Ruiz-Lozano P, Peterson KL, Croce CM, 
Peschle C, Condorelli G: MicroRNA-133 controls cardiac hypertrophy. Nat Med 2007, 13(5):613-618.

17. Sayed D, Hong C, Chen IY, Lypowy J, Abdellatif M: MicroRNAs play an essential role in the development of cardiac hypertrophy. Circ Res 2007, 100(3):416-424

18. Nakanishi N, Nakagawa Y, Tokushige N, Aoki N, Matsuzaka T, Ishii K, Yahagi N, Kobayashi K, Yatoh S, Takahashi A, Suzuki H, Urayama O, Yamada N, Shimano H: The up-regulation of microRNA-335 is associated with lipid metabolism in liver and white adipose tissue of genetically obese mice. Biochem Biophys Res Commun 2009, 385(4):492-496.

19. Esau C, Davis S, Murray SF, Yu XX, Pandey SK, Pear M, Watts L, Booten SL, Graham M, McKay R, Subramaniam A, Propp S, Lollo BA, Freier S, Bennett CF, Bhanot S, Monia BP: miR-122 regulation of lipid metabolism revealed by in vivo antisense targeting. Cell Metab 2006, 3(2):87-98.

20. Volinia S, Calin GA, Liu CG, Ambs S, Cimmino A, Petrocca F, Visone R, lorio M, Roldo C, Ferracin M, Prueitt RL, Yanaihara N, Lanza G, Scarpa A, Vecchione A, Negrini M, Harris CC, Croce CM: A microRNA expression signature of human solid tumors defines cancer gene targets. Proc Natl Acad Sci USA 2006, 103(7):2257-2261

21. Yanaihara N, Caplen N, Bowman E, Seike M, Kumamoto K, Yi M, Stephens RM, Okamoto A, Yokota J, Tanaka T, Calin GA, Liu CG, Croce CM, Harris CC: Unique microRNA molecular profiles in lung cancer diagnosis and prognosis. Cancer Cell 2006, 9(3):189-198.

22. Lewis $B P$, Burge $C B$, Bartel DP: Conserved seed pairing, often flanked by adenosines, indicates that thousands of human genes are microRNA targets. Cell 2005, 120(1):15-20.

23. Friedman RC, Farh KK, Burge CB, Bartel DP: Most mammalian mRNAs are conserved targets of microRNAs. Genome Res 2009, 19(1):92-105.

24. Griffiths-Jones S: miRBase: the microRNA sequence database. Methods Mol Biol 2006, 342:129-138.

25. Voorhoeve PM, le Sage C, Schrier M, Gillis AJ, Stoop H, Nagel R, Liu YP, van Duijse J, Drost J, Griekspoor A, Zlotorynski E, Yabuta N, De Vita G, Nojima H, Looijenga LH, Agami R: A genetic screen implicates miRNA-372 and miRNA-373 as oncogenes in testicular germ cell tumors. Cell 2006, 124(6):1169-1181.

26. Karolchik D, Baertsch R, Diekhans M, Furey TS, Hinrichs A, Lu YT, Roskin KM, Schwartz M, Sugnet CW, Thomas DJ, Weber RJ, Haussler D, Kent WJ, University of California Santa Cruz: The UCSC Genome Browser Database. Nucleic Acids Res 2003, 31(1):51-54.

27. Kent WJ, Sugnet CW, Furey TS, Roskin KM, Pringle TH, Zahler AM, Haussler D: The human genome browser at UCSC. Genome Res 2002, 12(6):996-1006.

28. Karolchik D, Hinrichs AS, Furey TS, Roskin KM, Sugnet CW, Haussler D, Kent WJ: The UCSC Table Browser data retrieval tool. Nucleic Acids Res 2004:D493-6

29. Griffiths-Jones S: The microRNA Registry. Nucleic Acids Res 2004:D109-11.

30. Griffiths-Jones S: miRBase: the microRNA sequence database. Methods Mol Biol 2006, 342:129-138.

31. Altschul SF, Gish W, Miller W, Myers EW, Lipman DJ: Basic local alignment search tool. J Mol Biol 1990, 215(3):403-410.

32. Chen C, Ridzon DA, Broomer AJ, Zhou Z, Lee DH, Nguyen JT, Barbisin M, Xu NL, Mahuvakar VR, Andersen MR, Lao KQ, Livak KJ, Guegler KJ: Realtime quantification of microRNAs by stem-loop RT-PCR. Nucleic Acids Res 2005, 33(20):e179.

33. Altuvia $Y$, Landgraf $P$, Lithwick $G$, Elefant $N$, Pfeffer $S$, Aravin $A$, Brownstein $\mathrm{MJ}$, Tuschl T, Margalit $\mathrm{H}$ : Clustering and conservation patterns of human microRNAs. Nucleic Acids Res 2005, 33(8):2697-2706.

34. Bentwich I: Prediction and validation of microRNAs and their targets. FEBS Lett 2005, 579(26):5904-5910.

35. Sempere LF, Freemantle S, Pitha-Rowe I, Moss E, Dmitrovsky E, Ambros V: Expression profiling of mammalian microRNAs uncovers a subset of brain-expressed microRNAs with possible roles in murine and human neuronal differentiation. Genome Biol 2004, 5(3):R13.

36. Miska EA, Alvarez-Saavedra E, Townsend M, Yoshii A, Sestan N, Rakic P, Constantine-Paton M, Horvitz HR: Microarray analysis of microRNA expression in the developing mammalian brain. Genome Biol 2004, 5(9):R68.

37. Yue J, Sheng Y, Orwig KE: Identification of novel homologous microRNA genes in the rhesus macaque genome. BMC Genomics 2008, 9:8.

38. Freemerman AJ, Wright RM, Flickinger CJ, Herr JC: Cloning and sequencing of baboon and cynomolgus monkey intra-acrosomal protein SP-10: homology with human SP-10 and a mouse sperm antigen (MSA-63). Mol Reprod Dev 1993, 34(2):140-148.

39. He PA, Nie Z, Chen J, Chen J, Lv Z, Sheng Q, Zhou S, Gao X, Kong L, Wu X, Jin $Y$, Zhang $Y$ : Identification and characteristics of microRNAs from Bombyx mori. BMC Genomics 2008, 9:248.

40. Wienholds E, Kloosterman WP, Miska E, Alvarez-Saavedra E, Berezikov E, de Bruijn E, Horvitz HR, Kauppinen S, Plasterk RH: MicroRNA expression in zebrafish embryonic development. Science 2005, 309(5732):310-311.

41. Weber MJ: New human and mouse microRNA genes found by homology search. FEBS J 2005, 272(1):59-73.

42. Bentwich I, Avniel A, Karov Y, Aharonov R, Gilad S, Barad O, Barzilai A, Einat P, Einav U, Meiri E, Sharon E, Spector Y, Bentwich Z: Identification of hundreds of conserved and nonconserved human microRNAs. Nat Genet 2005, 37(7):766-770.

43. Cox LA, Mahaney MC, Vandeberg JL, Rogers J: A second-generation genetic linkage map of the baboon (Papio hamadryas) genome. Genomics 2006, 88(3):274-281

44. Rogers J, Mahaney MC, Witte SM, Nair S, Newman D, Wedel S, Rodriguez LA, Rice KS, Slifer SH, Perelygin A, Slifer M, Palladino-Negro P, Newman T, Chambers K, Joslyn G, Parry P, Morin PA: A genetic linkage map of the baboon (Papio hamadryas) genome based on human microsatellite polymorphisms. Genomics 2000, 67(3):237-247.

45. Sempere LF, Freemantle S, Pitha-Rowe I, Moss E, Dmitrovsky E, Ambros V: Expression profiling of mammalian microRNAs uncovers a subset of brain-expressed microRNAs with possible roles in murine and human neuronal differentiation. Genome Biol 2004, 5(3):R13.

46. Zhang R, Peng Y, Wang W, Su B: Rapid evolution of an X-linked microRNA cluster in primates. Genome Res 2007, 17(5):612-617.

doi: 10.1186/1423-0127-17-54

Cite this article as: Karere et al., Identification of baboon microRNAs expressed in liver and lymphocytes Journal of Biomedical Science 2010, 17:54

\section{Submit your next manuscript to BioMed Centra and take full advantage of:}

- Convenient online submission

- Thorough peer review

- No space constraints or color figure charges

- Immediate publication on acceptance

- Inclusion in PubMed, CAS, Scopus and Google Scholar

- Research which is freely available for redistribution 